\title{
Correction to: Will the reformed Cancer Drugs Fund address the most common types of uncertainty? An analysis of NICE cancer drug appraisals
}

\author{
Liz Morrell ${ }^{1,2^{*}}$, Sarah Wordsworth ${ }^{2,3}$, Anna Schuh ${ }^{4}$, Mark R. Middleton ${ }^{4}$, Sian Rees ${ }^{5}$ and Richard W. Barker ${ }^{1}$
}

\section{Correction to: BMC Health Serv Res (2018) 18:393 \\ https://doi.org/10.1186/s12913-018-3162-2}

In the original publication of this article [1], the Acknowledgements section lacks of important funding information "This project was funded by the NIHR Oxford Biomedical Research Centre BRC". The authors apologize for any inconvenience that it may have caused.

\begin{abstract}
Author details
'Oxford-UCL Centre for the Advancement of Sustainable Medical Innovation, Radcliffe Department of Medicine, University of Oxford, Room 4403, Level 4, John Radcliffe Hospital, Headley Way, Headington, Oxford OX3 9DU, UK. ${ }^{2}$ Health Economics Research Centre, Nuffield Department of Population Health, University of Oxford, Old Road Campus, Roosevelt Drive, Headington, Oxford OX3 7LF, UK. ${ }^{3}$ Oxford NIHR Biomedical Research Centre, University of Oxford, Oxford, UK. ${ }^{4}$ Department of Oncology, University of Oxford, Old Road Campus Research Building, Roosevelt Drive, Headington, Oxford OX3 7DQ, UK. ${ }^{5}$ Health Experiences Institute, Nuffield Department of Primary Care Health Sciences, University of Oxford, 23-38 Hythe Bridge Street, Oxford OX1 2ET,
\end{abstract} UK.

Published online: 28 March 2019

\section{Reference}

1. Morrell, et al. Will the reformed Cancer drugs fund address the most common types of uncertainty? An analysis of NICE cancer drug appraisals. BMC Health Serv Res. 2018;18(393). https://doi.org/10.1186/s12913-018-3162-2.

\footnotetext{
* Correspondence: liz.morrell@ndph.ox.ac.uk

'Oxford-UCL Centre for the Advancement of Sustainable Medical Innovation, Radcliffe Department of Medicine, University of Oxford, Room 4403, Level 4, John Radcliffe Hospital, Headley Way, Headington, Oxford OX3 9DU, UK ${ }^{2}$ Health Economics Research Centre, Nuffield Department of Population Health, University of Oxford, Old Road Campus, Roosevelt Drive, Headington, Oxford OX3 7LF, UK

Full list of author information is available at the end of the article
}

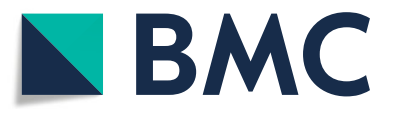

(c) The Author(s). 2019 Open Access This article is distributed under the terms of the Creative Commons Attribution 4.0 International License (http://creativecommons.org/licenses/by/4.0/), which permits unrestricted use, distribution, and reproduction in any medium, provided you give appropriate credit to the original author(s) and the source, provide a link to the Creative Commons license, and indicate if changes were made. The Creative Commons Public Domain Dedication waiver (http://creativecommons.org/publicdomain/zero/1.0/) applies to the data made available in this article, unless otherwise stated. 